\title{
BIOPHILIC DESIGN FEATURES IN VERNACULAR ARCHITECTURE AND SETTLEMENTS OF THE NAXI
}

\author{
Mengbi LI (1) ${ }^{1}$, Hing-Wah CHAU (D) ${ }^{2}$, Lu AYE (1D) ${ }^{* *}$ \\ ${ }^{1}$ First Year College, Institute for Sustainable Industries and Liveable Cities, Victoria University, Melbourne, \\ Footscray, 3011, Victoria, Australia \\ ${ }^{2}$ Built Environment Discipline Group, College of Engineering and Science, Institute for Sustainable Industries and \\ Liveable Cities, Victoria University, Melbourne, Footscray, 3011, Victoria, Australia \\ ${ }^{3}$ Renewable Energy and Energy Efficiency Group, Department of Infrastructure Engineering, Melbourne School of \\ Engineering, The University of Melbourne, 3010, Victoria, Australia
}

Received 25 August 2020; accepted 10 November 2020

\begin{abstract}
As a newly formed concept, "Biophilic design" is attracting a growing attention among both practitioners and academics. However, the link between biophilic design and vernacular architecture has yet to be thoroughly explored, especially in the context of China, which is the gap this article aims to fill. Investigating the vernacular architecture of the Naxi, this research found that biophilic design attributes and features existed in vernacular buildings and settlements. A matrix framework was developed to facilitate the in-depth investigation of the interrelated elements of the Naxi such as local climate, topography, culture, their belief system, conventions, arts and literature. Among other results, we found that the local culture was influenced by animism and distinct cosmic models. Also, the buildings were constructed using the traditional ways of material preparation and conventions of occupancy. This research serves as an important springboard to bridge between studies in biophilic design and studies in vernacular architecture and settlements.
\end{abstract}

Keywords: vernacular architecture, biophilia, biophilic design, traditional culture, the Naxi, China.

\section{Introduction}

Biophilic design is a concept that emerged around 2008 (Kellert et al., 2008). Since then, many architects and scholars have explored the patterns adopted for the biophilic design and the benefits obtained from biophilic features (Kellert, 2018; Hui \& Aye, 2018; Söderlund, 2019; Browning \& Ryan, 2020). ${ }^{1}$

As an enduring built form, vernacular architecture and settlements show a profound connection with the natu-

\footnotetext{
1 "Biophilic design" is a concept based on the Greek-origin word, biophilia, which means, "love of life". In 1959, Heinz Hartman first noted human's particular affiliation to nature and proposed this concept in his book Psychoanalysis and Moral Values, see Hartmann (1959). According to Marianne Horney Eckardt, Erich Fromm first adopted the term "biophilia" in 1961, see Eckardt (1992). The term continued in Fromm's The Heart of Man (Erich, 1964). Following that, Edward O. Wilson defined the concept as "the urge to affiliate with other forms of life”, see Fennell (2006); Ramzy (2015).
}

ral environment and other forms of life (Knapp, 1992). Moreover, inhabitants' strong attachment to nature in their day-to-day life and inhabitation in largely self-built buildings present some interesting features that resonate the concept of biophilia. ${ }^{2}$ A natural question is how can we unravel these profound yet complex biophilic connections in vernacular architecture and settlements?

Research in the area of biophilic design has the potential to strengthen studies in vernacular architecture and settlements. Recent research in this area provides a systematic explanation of why people need to maintain an attachment to nature through built environment

\footnotetext{
2 Some studies focusing on biophilic design have implied the potential of involving studies in vernacular architecture and settlements. For example, when Terrapin researchers (Browning et al., 2014) analysed biophilic design patterns, they celebrated the vernacular's positive response to topography, climate, regional ecology and local materials. Although this is an abstract mention, it casts light on a momentum.
}

*Corresponding author. E-mail: lua@unimelb.edu.au

Copyright $\odot 2020$ The Author(s). Published by Vilnius Gediminas Technical University

This is an Open Access article distributed under the terms of the Creative Commons Attribution License (http://creativecommons.org/licenses/by/4.0/), which permits unrestricted use, distribution, and reproduction in any medium, provided the original author and source are credited. 
(Heerwagen, 2006), particularly through patterns or attributes (Kaplan \& Kaplan, 1989; Jo et al., 2019; Frumkin, 2001; Kellert et al., 2008; Alvarsson et al., 2010; Keniger et al., 2013; Ryan et al., 2014). These investigations provided an important reference to better understand vernacular architecture and settlements. First, this study offers a new perspective to observe the relationship between local communities, regional natural environment and the corresponding vernacular morphology of buildings and settlements. Second, the concept of biophilic design is not only a pathway to better understand the local built environment but also a channel to reveal knowledge and practices accumulated through existing experience and praxis, especially the innate affiliations of human beings with nature and natural elements (Kellert, 2005; Ramzy, 2015). On the other hand, studies in vernacular architecture and settlements may offer some lessons for biophilic design. It may also serve as a sounding board for people and local traditions to support further explorations in biophilic design and the inter-relationship between urban sustainability and biophilic urbanism (Kremer et al., 2019; Yigitcanlar et al., 2019).

To our knowledge, there has been a lack of study that cuts across the areas of biophilic design and vernacular architecture. This article is expected to fill this gap by providing a better understanding of the link between these two areas, especially in a context of China. Recent studies indicated that there is a large potential to pursue this direction, but it remains unexplored about "How can we bridge the biophilic design with studies in vernacular architecture and settlements?"

This study first develops a pertinent approach for observation and analysis, and then applies it to the case of the Naxi and further enquires: What are the biophilic design features in this case and why do they matter? The Naxi people live in south-western China, a remote and mountainous area. Despite the prevailing urbanisation, the Naxi has maintained many particular ways of life and traditional vernacular architecture and settlements. Today, an increasing number of visitors and tourists are attracted to the Naxi's region each year. There may be many reasons for this, but it is arguable that the connections with nature aspect of the vernacular architecture and settlements is one of them (Jiang, 1997a, 1997b; J. Wang \& T. Wang, 2008). The Naxis culture has a strong sense of animism ( $\mathrm{Li}$, 1991; Chen, 2008; Zheng \& Liu, 2006; Yang \& Zhu, 2009), which is reflected in their buildings, villages and towns. To delve into vernacular architecture and settlements, a historical and cultural perspective is critical, particularly in the context of the Naxi (Carsten \& Hugh-Jones, 1995; Lévi-Strauss, 2008; Pan, 2014; Rapoport, 1969; Ruan, 2006; Wang, 2013; Waterson, 2013). To this end, this study attempts to integrate historical and cultural studies with architectural studies to discuss biophilic design features observed in vernacular architecture and settlements of the Naxi, using an innovative new matrix developed based on the seminal models of biophilic design.

\section{Methods}

Two models of biophilic design have been proposed in the literature. First, based on an analysis of human's well-being and its connections to nature, Stephen R. Kellert critically reviewed approaches to design, and discussed how to mitigate the emerging challenges and achieve a restorative environmental approach. In his study, a model of six elements was formed (Kellert, 2008). The first three elements: environmental features, natural shapes and forms, natural patterns and processes are related to nature. The fourth element, light and space, involves both nature and place. The remaining two elements, place-based relationships and evolved human-nature relationship are linked to place and people respectively. Kellert's six biophilic elements can be categorised under the three essential pillars of the design concept: nature, place and people, which are reflected in Figure 1. The second model with three main categories and 14 patterns was proposed based on an analysis of the notion of nature and biophilia as well as a number of design cases (Browning et al., 2014).

While the two models have several merits, they can be further developed through deconstructing and resynthesizing their components for observing biophilic design features. Pertinent to this study, these models not only provide a well-signposted map to guide biophilic design but also introduce a framework that considers social, cultural, scientific and artistic features of biophilic design. However, these models involve overlapping between patterns, cross-referencing of features, and recurrences. Take the model by Browning, Ryan and Clancy as an example. Under the category of "nature of the space patterns", the fifth pattern "presence of water" is often used to explain the other patterns including "visual connection with nature", "non-visual connection with nature", "non-rhythmic sensory stimuli", "thermal and airflow variability". In addition, "presence of water" is also referred in the patterns under other categories, it also serves as an important feature in multiple patterns, including, "dynamic and diffuse light", and "connection with natural systems". Similar cross-referencing exists in many other scenarios.

The presence of such cross-referencing and overlapping is due to the nature of the concept of biophilic design. In this concept, there are a plethora of factors to be considered. Thus, it is instrumental to provide a clear roadmap to incorporate the factors of biophilic design and illustrate their complex interrelations. The intertwined relationships among the three pillars of nature, place and people can be visualised in Figure 1. Based on these three pillars, the 14 patterns of biophilic design proposed by Browning et al. (2014) and biophilic design attributes presented by Kellert (2008) can be synthesised into a matrix in Figure 2.

Firstly, from the aspect of "nature", there are three domains from straightforward direct to indirect: natural feature; natural shape and form; natural analogue, pattern and process. Secondly, from the aspect of "people", there are two domains of focus: physical and psychological connections with nature. Physical connection with nature is 


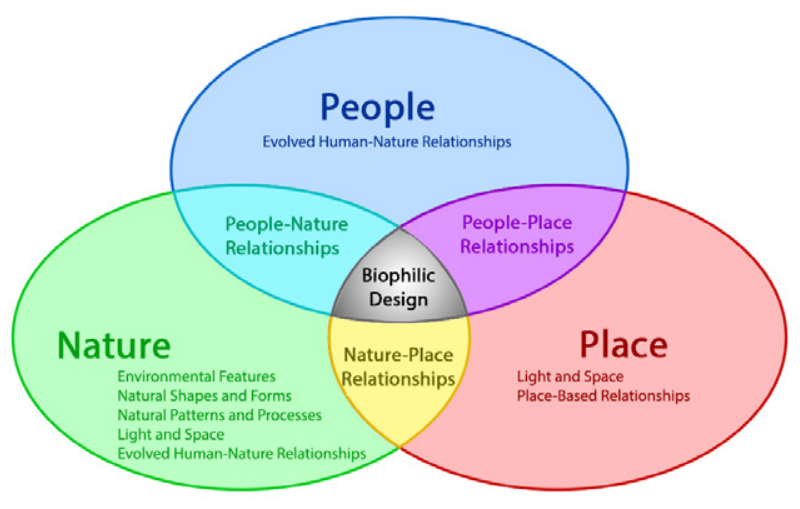

Figure 1. Three pillars and their intertwined relationships (diagram by the authors)

divided into five subdomains: visual connections; somatosensory connections (thermal and tactile sensations); auditory, olfactory and gustatory connections. Psychological connection with nature (intelligent interpretation of nature) has four subdomains: prospect; refuge; mystery; and risk/peril. Finally, from the aspect of "place", the biophilic design features in relation to "architecture and settlement" can be categorised into multiple subdomains, including region, settlement: grid and axis; street, road, lane and circulation; site: landscape; built form: material; construction; spatial demarcation; meaning. The detailed intertwined relationships among the three pillars can be visualised in the form of a matrix (Figure 2).

Based on this three-pillar matrix (Figure 2), a focused observation on place in relation to vernacular architecture and settlements of the Naxi will serve as a criterion checklist. This attempt would serve as a pilot observation and analysis for bridging areas of biophilic design and vernacular architecture.

Some biophilic design features are conspicuous and they are concretised in the physical built environment, while some features can be less tangible, such as features that involve psychological connections with nature. For the latter, a multidisciplinary perspective would be helpful to assist a comprehensive observation. For example, in the case of the Naxi, this study shows that taking the local culture into consideration leads to a better understanding of the local people's particular connection with nature. Therefore, local history, culture, and onsite fieldwork played an important role for us to understand those meaningful but less tangible features.

\section{Results}

This section presents the findings of this study by applying the three-pillar matrix developed for observing biophilic features. In this implementation, the second pillar "place" serves as the key thread of the observation. This means that all the features noticed in the Naxi's architecture and settlements are analysed against their association with the other two pillars of "nature" and "people". As such, salient biophilic features will be elaborated around the pillar of "place" and analysed against the other two pillars according to the mapped pathways in the matrix.

Like many other regions, the settlements of the Naxi have been influenced by urbanisation and tourism. The Naxi's historic town Dayan (Old Town of Lijiang) is one of the only two towns in China that are recognised as a UNESCO World Heritage Site (both towns were listed in 1997) (United Nations Educational, Scientific and Cultural Organization [UNESCO], 2020). The region's prestige and beauty attracted a large number of tourists and visitors every year. Correspondingly, the reconstructions of some major buildings do not follow the historical design, which has significantly transformed the fabric of local townscape (Su \& Teo, 2009). Therefore, unravelling and recording these vernacular approaches and features has become increasingly pressing and significant. This will help bring broader audiences from different disciplines together to investigate the biophilic design features. Also, it will facilitate these local people's knowledge practices, and innate senses of biophilia to be documented.

\subsection{Region and settlement}

The settlements of the Naxi were located at the southern foot of Yulong Snow Mountain. A visual and cultural connection with Yulong Mountain was maintained for residents in the Naxi's settlements (Figure 3). The axis of the
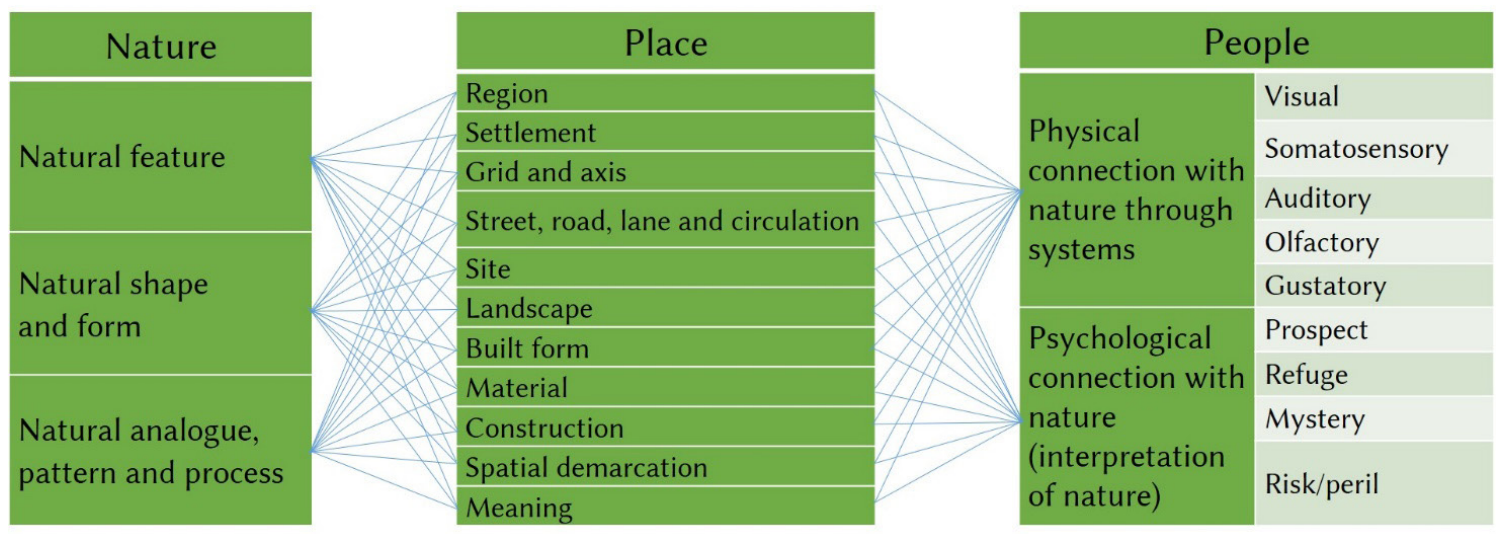

Figure 2. A matrix for observing biophilic design features (diagram by the authors) 

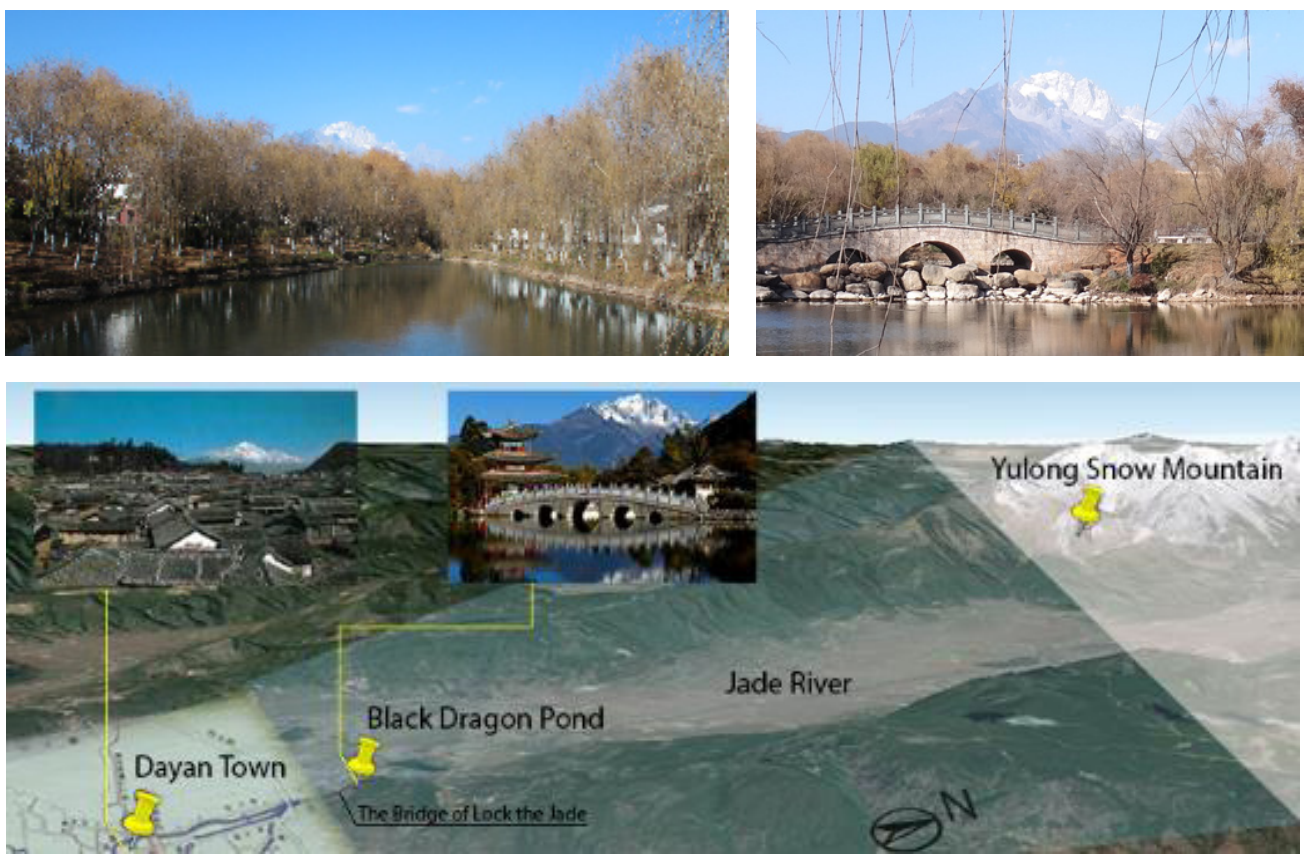

Figure 3. Yulong Snow Mountain viewed from the Naxi's settlements (photos by the first author; analysis diagram based on the satellite image from Google earth)

main street acted as a view towards the mountain. Beyond a simple visual connection with natural environmental features, this relationship had been endowed with cultural meaning and practical significance.

The profound cultural connection with the natural element, Yulong Snow Mountain, is indicated by a local anthropomorphic deity, sanduo 三多. Sanduo was the patron saint of the Naxi. Every year, on the date of goat in February and August, the Naxi worshipped this important deity in the Sanduo Temple called beiyue miao 北岳庙 (Temple of Northern Mountain). The "Northern Mountain" for the Naxi was Yulong Snow Mountain. ${ }^{3}$ In fact, Yulong Snow Mountain was regarded as the incarnation of the deity Saduo. ${ }^{4}$

As a result, beyond a natural element in the local region, Yulong Snow Mountain was holy place that were highly respected by the local people. More than a visual connection with the natural landscape, particularly mountains, there were psychological connections in the local

3 The History of the Naxi's Culture and The Unofficial History of Nanzhao recount how people related Yulong Snow Mountain with Sanduo. That history can be traced back to the Tang dynasty. In Fourth Zhenyuan year 贞元四年 (779 CE), Yimouxun 异牟寻, the king of the Nanzhao Kingdom, designated "holy mountains", and among them Yulong Snow Mountain was the Northern Mountain, see Wang (1957). When the chieftain of the Naxi rebuilt Sanduo Temple, he kept a record of this, which was titled “重修北岳庙记” (A record of rebuilding Northern Mountain Temple), see He (2001).

4 The couplet hung on the right in the Sanduo Temple at Baisha Village was “三多乃雪岳身影雪岳乃三多身容身常修德身 宏昌” (Sanduo's clothes are snowy white. He is righteous and morally perfect). belief system. Because of this, this feature is connected with nature through both visual system and psychological connections.

From a pragmatic perspective, the abundant highquality water resources from Yulong Snow Mountain form a network of catchments around it. The town benefited from this supply and formed particular townscape and amenities (Yang, 2009). This will be analysed later when we look at the town's relationship with water, which is an important natural element.

In terms of geography and climate, the location of the Naxi's principal settlement in Lijiang has two advantages. One is a complementary relationship between the regional landform and the local wind. In the region, the wind can be strong (Figure 4) and largely influences the microclimate of the habitat of the local community. The town is located in a basin surrounded by mountains (Figure 5). This topography is helpful for maintaining a mild local climate $^{5}$.

Therefore, the Dayan town has a connection with natural features, more specifically, the natural landscape - mountains. The connection includes physical connection through

\footnotetext{
5 In winter, the dominant direction of wind is northwest and the wind is cold and long-lasting with high speeds $\left(3-10 \mathrm{~m} \mathrm{~s}^{-1}\right)$. Dayan is a historical capital town of the Naxi and locates in the centre of today's Lijiang, on the south of the large mountains. These mountains protect the town from the prevailing wind from the northwest in winter (Zhu, 2011; Jiang, 1997a, 1997b; Yang \& Zhu, 2009). The southeast side and a small portion of the west side are comparatively open. The west side is enclosed by highland, but there is a small gap. The southeast side is open. Interestingly, in summer, the wind from southeast prevails in Lijiang. It can bring cooler airs and ventilate the area.
} 

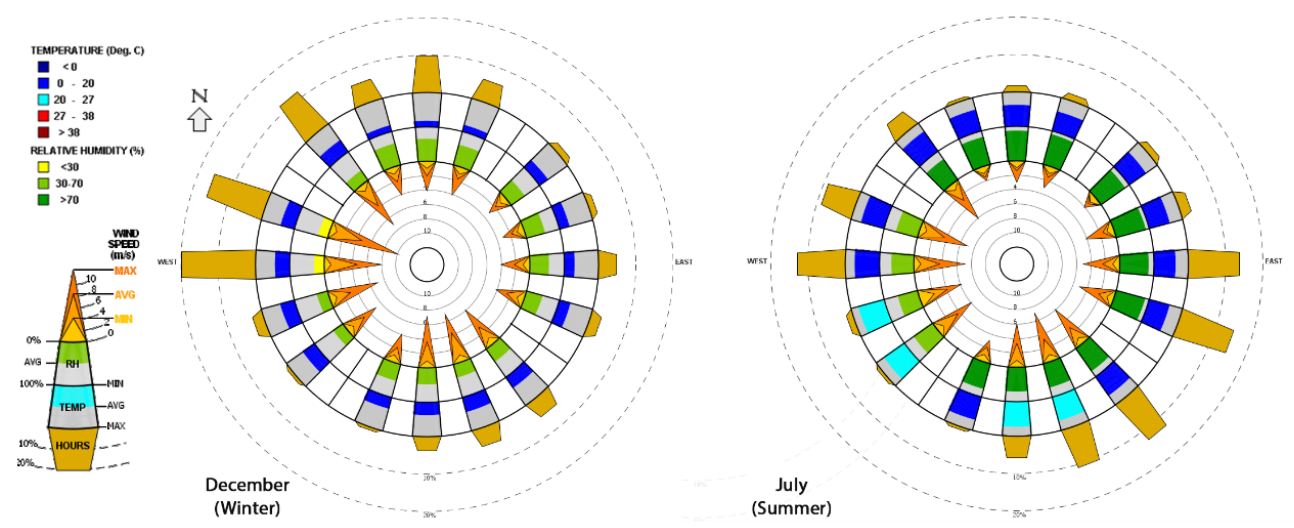

Figure 4. Wind wheels of Lijiang winter (left) and summer (right) (diagrams generated with Climate Consultant 6.0 (Liggett \& Milne, 2020) and EnergyPlus weather data (EnergyPlus, 2020))
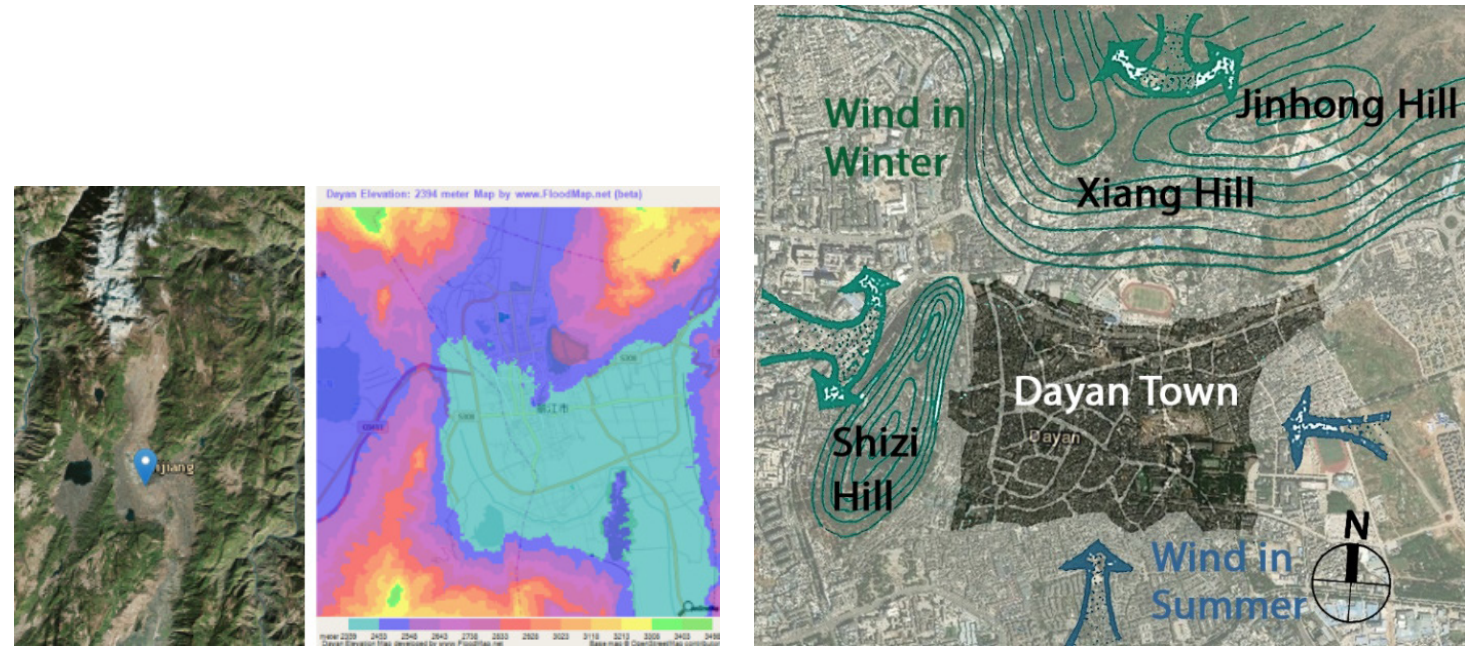

Figure 5. The topography surrounding Lijiang where the Naxi mainly lived (left: satellite image from OpenStreetMap; middle: from FloodMap and OpenStreetMap; right: by the first author)

visual system and psychological connection. It also relates to thermal sensation through the mediated temperature. The advantage of the landform is an important reason for the Naxi community to enjoy a mild temperature about $13{ }^{\circ} \mathrm{C}$, although the basin area of their settlements has a high altitude of $2.416 \mathrm{~m}$ and is close to large snow mountains.

The basin surrounded by mountains in this particular form has a long record of human's settlements. According to archaeological findings, as early as two million years ago, local people have inhabited there (Zhou, 1999). In 111 BCE during the Western Han dynasty (206 BCE-9 CE), Suijiu county that was under Yuesui prefecture was built over there. In $585 \mathrm{CE}$ during the Sui dynasty (581-618 CE), Xiu county governed by Nanling State was established (He, 2011). Throughout subsequent dynasties, this has always been a popular area for people to live.

\subsection{Grid, street and circulation}

Around the world, there are many cities and towns with street patterns based on orthogonal grids, such as Xian, Beijing, Melbourne, Turin, etc. Accordingly, buildings are built along the streets and form regularly-shaped blocks. As early as the Western Zhou dynasty, there have been codes for craftspeople that demonstrated streets according to longitudinal and latitudinal axes (Wen, 2008). However, the Dayan town presented a complex circulation network with circuitous grids. According to the local chronicles, as early as late Southern Song dynasty (1127-1279 CE), the local community had developed an approach to form the fabric of their settlements following the networks of flowing water (He, 2011; Zhu, 2005).

This connection with the natural environmental element-water, plays an important role in the urban fabric of the Naxi's settlement. The area of the Dayan town has a network of water flowing from north to south that consists of multiple ponds, streams and creeks (Figure 6, Figure 7). In the north of the Dayan town is Heilong Tan (Black Dragon Pond). Water from this pond flows into Yu River (Jade River) and then separates into three main branches, namely Xi River (Western River), Zhong River (Middle River) and Dong River (Eastern River). The Western River was a canal channelled during early years of Emperor 

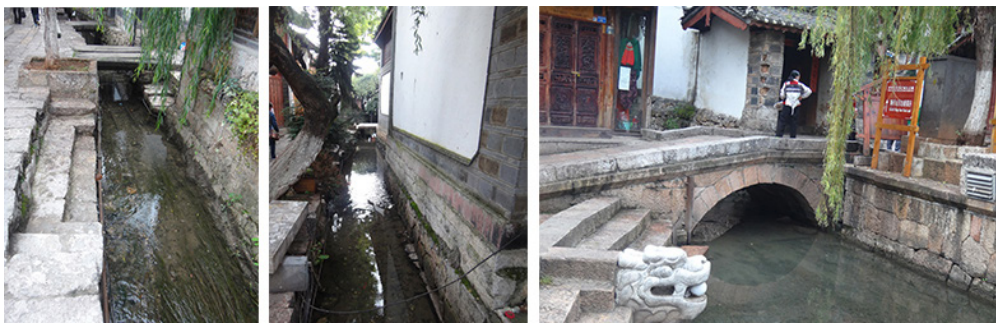

Figure 6. Streams, creeks, streets and bridges (photos by the first author)
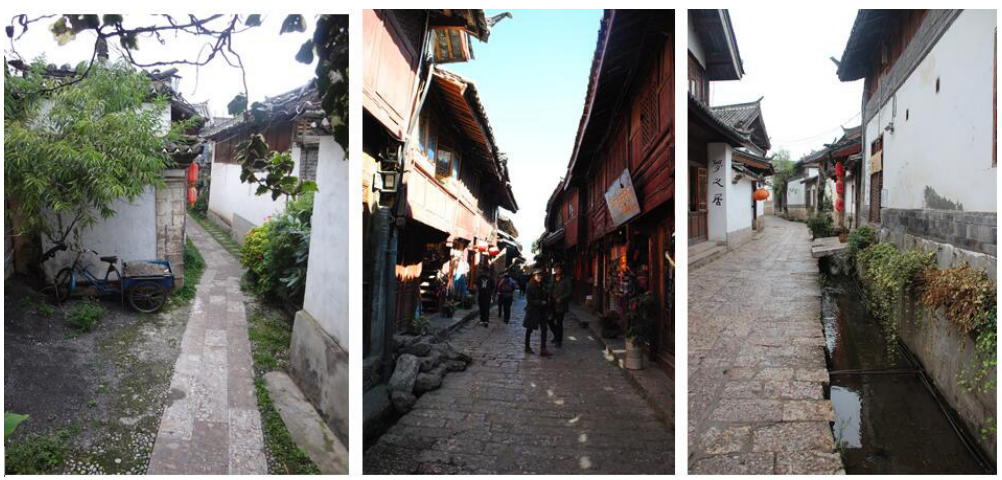

Figure 8. Circuitous streets and lanes (photos by the first author)

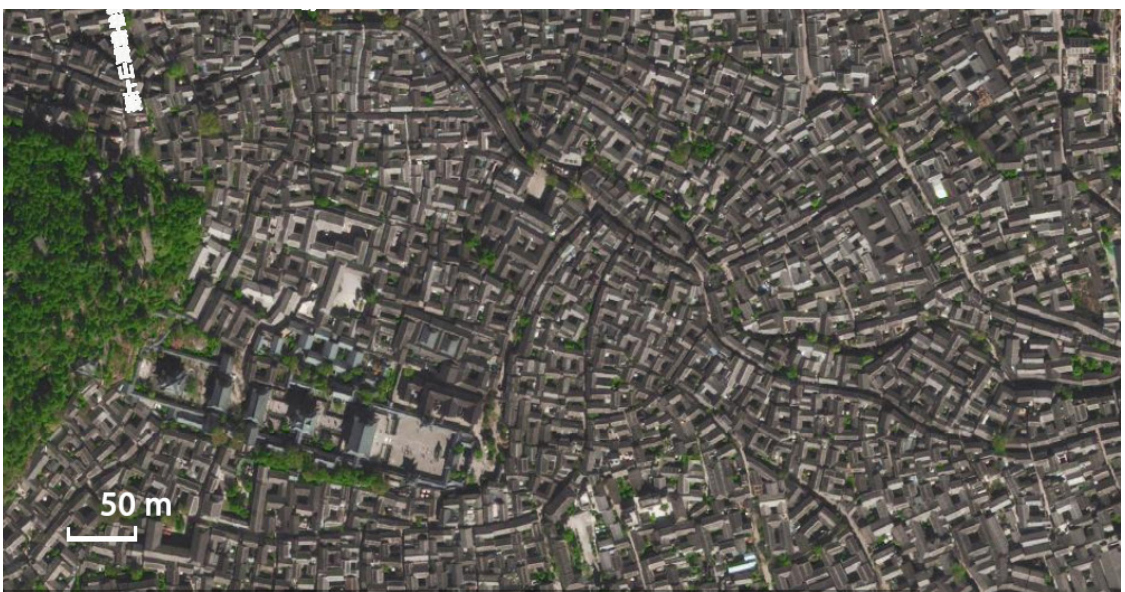

Figure 9. The urban fabric of Dayan town (Satellite map from Baidu Map)

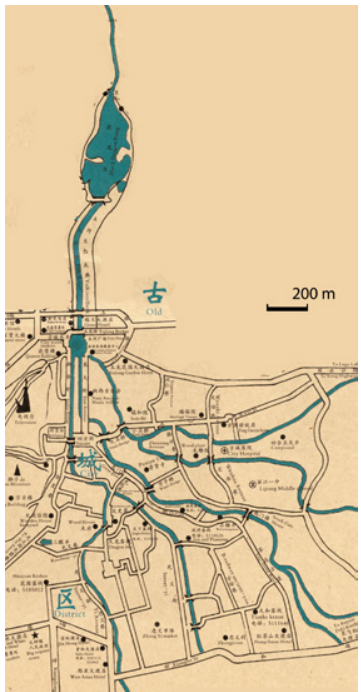

Figure 7. A map of Dayan, historical town in the Naxi's region with streams marked (Baomanfeng map)
Yongzheng of the Qing dynasty in reign (1722-1735 CE) to reserve some water for irrigating farms in the east $(\mathrm{He}$, 2011). Splitting from these three main branches, a number of streams and creeks enriched this network of water channels. The usual orthogonal axis did not serve as grids of the town; instead, streets and buildings went along the pathways of flowing water (Figure 8, Figure 9). As a consequence, the biophilic design approach of utilising waterfront today could be observed through their vernacular implementations in a number of cases around the Naxi's settlements. This network of water channels also formed a utility network.

Grids were generated from "natural patterns and process" and directly connected with "natural feature", water. The visual connection with the flowing water is visible throughout the town, accompanied by the auditory connection with the flowing water and psychological connec- tions. In 1963, a prestigious litterateur and scholar in Chinese recent history, Guo Moruo, metaphorically described the streets in Dayan as "flying dragons" along the pathways of flowing water. This verse written by Guo Moruo is currently exhibited in Heilongtan in Lijiang.

\subsection{Landscape}

Courtyards and patios were an indispensable part of the Naxi's day-to-day life. Especially, the elders who are living a traditional way of life, enjoyed gardening and pets in their courtyards and patios. This reflects the biophilic design feature of connection to "natural features". In addition, the multisensory connection with nature was also fulfilled. During the author's fieldwork, it was found that the courtyards were full of plants (Figure 10). Rather than being exposed to the exterior of the house, 

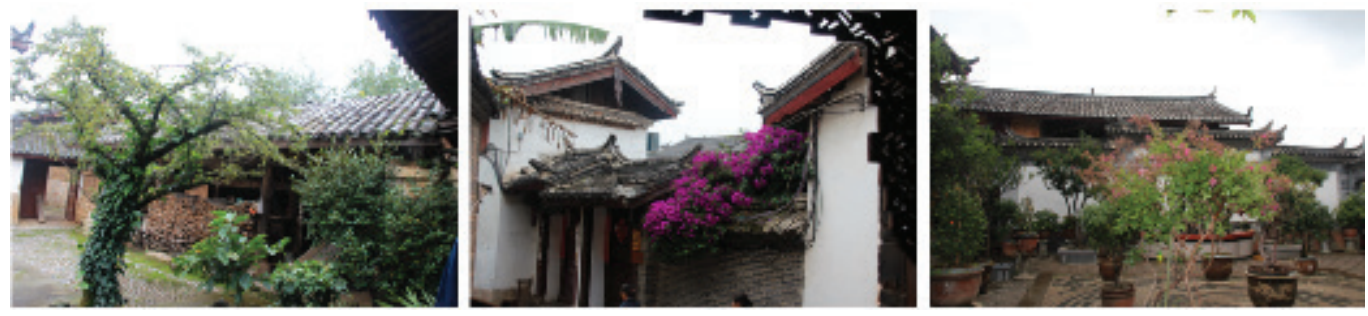

Figure 10. Courtyards full of plants (photos by the first author)
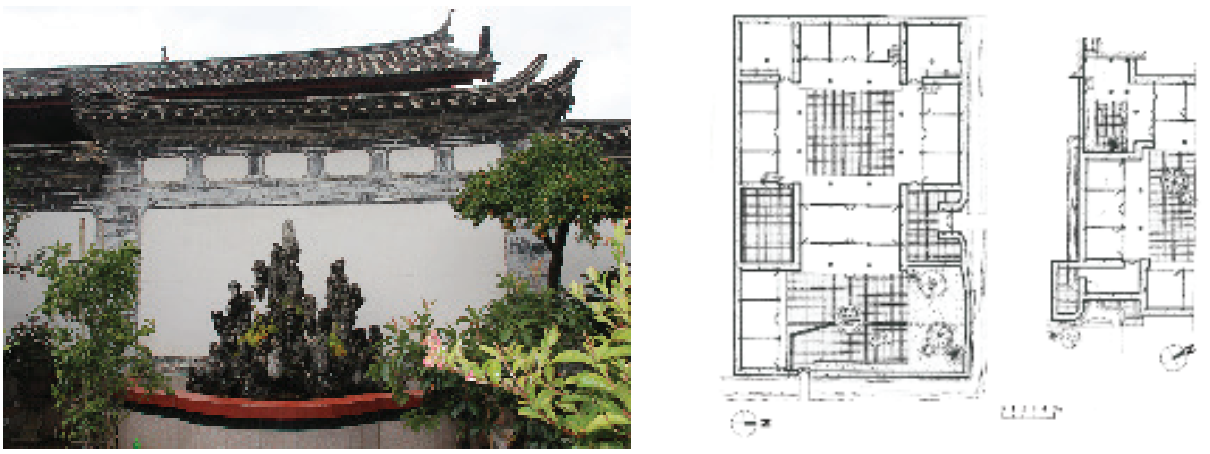

Figure 11. Water feature in courtyard (left) (photo by the first author); floor plan of cases that channelled water from external creeks into courtyards (right) (source: Zhu, 2020; personal communication, 18 January)
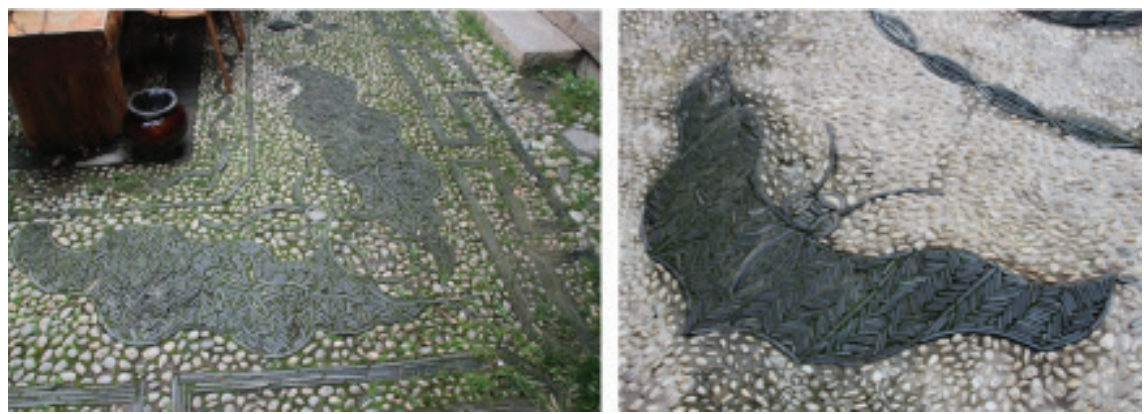

Figure 12. Pavement with patterns of bats (photos by the first author)
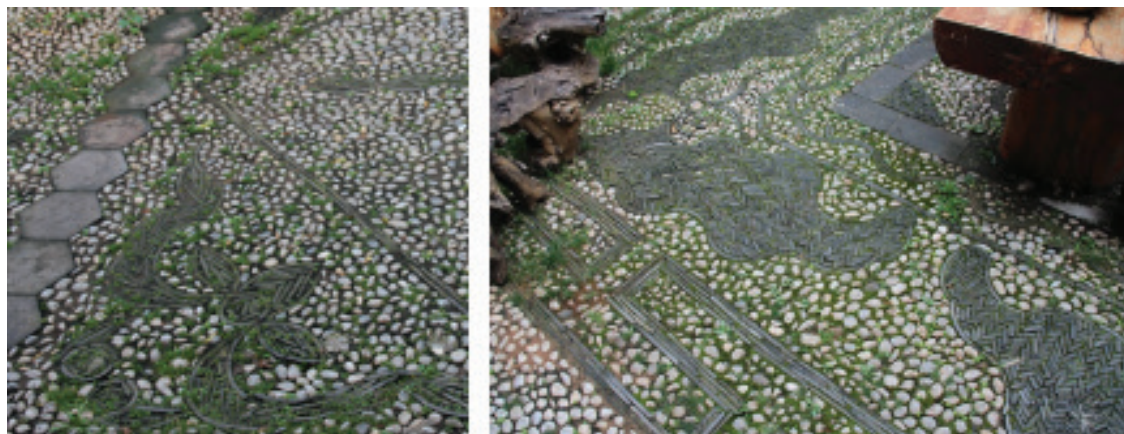

Figure 13. Paving with pebbles, tiles and bricks (photos by the first author)

these domestic landscapes are enclosed inside the central courtyard of the building. The aroma of flowers and the humming of birds fulfilled an "auditory and olfactory" experiences. It should be noted that in several cases, the water from nearby streams or creeks were channelled into the courtyards and formed flowing water features that connected the internal and external of the houses (Figure 11).
"Natural shapes and forms" as well as "natural analogues" and "natural patterns and process" features were observed in the courtyards and patios. These include not only the plants, animals and water features but also meticulously paved ground. Tiles, cobbles and bricks were used to pave out patterns of natural shapes on the ground of their courtyards. These patterns were more than simple decorations. They were symbols with special mean- 
ings. Different symbols represented different messages. For example, the "bat" pattern was popular (Figure 12), because it represented good luck and auspiciousness. The word "bat" is pronounced the same as $f u$ 福 (good luck and auspiciousness). This way of paving the ground benefits "thermal sensation" as well. It helped to adjust the microclimate of the courtyard house, allowing grass and moss to grow through the gaps between the cobbles or bricks (Figure 13), collecting the rainwater and providing evaporative cooling effect.

\subsection{Site and building}

Light, particularly daylight, is recognised to be very important for biophilic design. In Kellert's biophilic design model, "light and space" is identified as one of the six fundamental biophilic design elements. In the category of this element, 12 attributes are identified. In the model of biophilic design by Browning, Ryan, and Clancy, light serves as one of the 14 patterns and is termed as "dynamic \& diffuse light". This study notes that daylight was creatively arranged in the vernacular houses of the Naxi through managing the relationship between building sites and courtyard houses.

One of the typical features that prevailed among the majority of traditional Chinese buildings is orientation. Facing south towards the sun was seen as a supreme priority among the four cardinal directions. ${ }^{6}$ Traditional Chinese buildings were usually built in the form of siheyuan, which means a house with a central square or rectangular courtyard surrounded by buildings and/or walls on each side. The most important wing of the building, namely the main hall, was built to face the south or with a small angular deviation clockwise or anticlockwise from the due south.

There were two patterns observed in the vernacular buildings of the Naxi. They were relevant to the settlement feature of introducing circuitous waterways as the grids. The first feature was the preferred building orientation of east or southeast. For example, in the house of the Lis located 41, Xinghuo Lane, Qiyi Street, built in 1938 $\mathrm{CE}$, the orientation of the main hall building was southeast (Case A). The same orientation appeared in the house of the Zhaos located 489, Renmin Street, built about one hundred years ago (Case B). The main hall of the house of the Hes, 87, Xinhua street faced east (Case C).

Why was there a different preference of orientation? The feature of local solar exposure and local belief system may have contributed to this preference. The Naxi people believed in Dongba, a local religion that shows con-

\footnotetext{
${ }^{6}$ Culturally, south is in preference to north in premodern China. In the premodern Chinese language, north was used to represent failure. Historical literature, such as Shiji and Dixuezhizheng, have relevant records and elaboration which shows that south was a preferred orientation for buildings. In ancient times, the east could be a preference. Relevant records can be found in Chunqiuzuozhuan.
}

nections to Daoism. Dongba has a conspicuous character of animism. For example, the compass of the Naxi was similar to the one applied in Fengshui, but it consisted of many distinctive ideas from Dongba. Four natural elements represented the four cardinal directions. Twelve zodiac animals were integrated into the finer subdivisions of the azimuth $(\mathrm{Li}, 1991)$. Space and time were combined in the measurement and calculation of orientations in a particular way. In terms of sunlight, the local solar radiation received on the west side of the building is high. Shading is necessary for any fenestration towards the west, while openings towards south or east are necessary for maximising winter solar exposure. Passive solar direct gain with high thermal mass design could make about $21 \%$ of the time thermally comfortable (Figure 14) reference to (American Society of Heating, Refrigeration, and Air Conditioning Engineers [ASHRAE], 2004, Standard 552004). Another contributor was the direction of the prevailing wind. In winter, the cold prevailing wind was from west or northwest, and in summer, the preferred prevailing wind was from the southeast. Therefore, an orientation towards southeast or east was more suitable for a preferred connection with the important natural feature, solar exposure. Moreover, this orientation also benefits a better connection with the wind. Taking both the cultural and environmental factors into consideration, the local choice of orientation seems appropriate.

The second feature was the arrangement of site and buildings. Although the formal model of the Naxi's vernacular buildings followed siheyuan, it had a comparatively unconventional arrangement of entries, patios and courtyards. This feature may be a result of combined factors. Three factors may be prominent, including the particular structural system of local buildings, the composition of courtyard houses and the circuitous grids of the settlement. The sites of buildings were along the network of waterways, therefore the orientation of sites varied. However, the footprint outline of local buildings was rectangular and had very limited flexibility, because the vernacular construction process followed the structural system of column-and-tie. Columns were joined into a transversal frame and the transversal frames were connected by longitudinal beams.

The structural system determined the rectangular footprint of buildings, so how can the preferred orientation of southeast or east be guaranteed along with the circuitous grids of streets? For example, in Case A (Figure 15), the main hall did not face the street but was rotated to face southeast towards its side-by-side house of the neighbour's. In front of the main hall was the central courtyard and behind the courtyard was a high solid wall built in the form of a zhaobi (also known as screen wall). ${ }^{7}$ Behind the zhaobi was a narrow patio in an irregular shape that was similar to an oxygon with a very sharp acute angle

\footnotetext{
7 For more information about the element of the zhaobi, see Li (2020).
} 


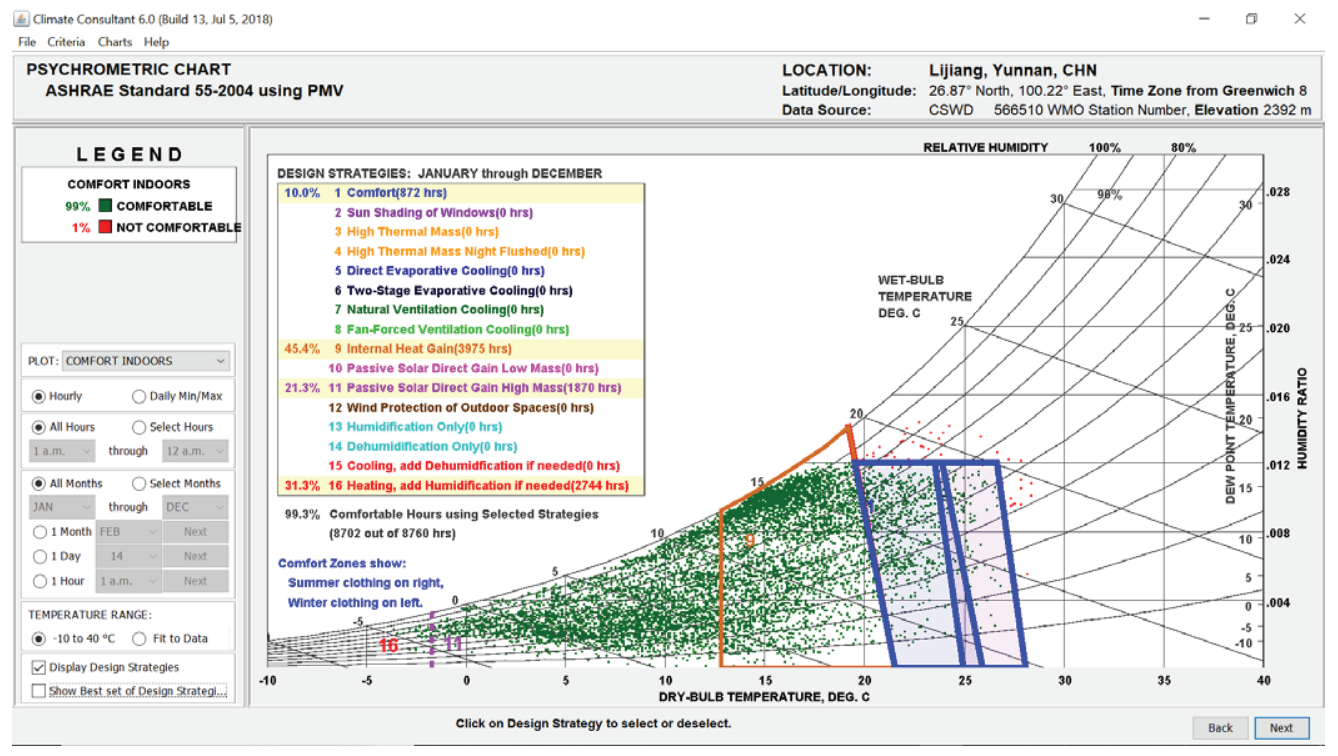

Figure 14. Appropriate building design strategies for Lijiang (diagram generated with Climate Consultant 6.0 (Liggett \& Milne, 2020) and EnergyPlus weather data (EnergyPlus, 2020))

wedging into the southeast side of the courtyard house. Accordingly, the entry was built at the south-western corner. With these geometric assemblies, the orientation was corrected from the circuitous grid and guaranteed a façade towards southeast for the main hall. Concurrently, this façade with a large proportion of openings could have sufficient buffers between it and the neighbour's house, although it faced towards the neighbour.

In Case B (Figure 16), two connected courtyards were built, but they were not connected in a linear way with the second courtyard built behind the first courtyard's main hall. These two courtyards were side by side and each of them had a separate entry. On the southeast side, an irregularly shaped courtyard was built as a long and narrow polygon. There were two entries respectively located along the tilt edge in the east and a straight edge of the southeast.

In Case C (Figure 17), the entire courtyard house was in L-shape with three main courtyards. The main hall was built at the innermost corner that was at the junction of the two wings, facing east. The courtyard located at the front end was built in irregular shapes. In order to minimise the earthwork, this case adopted an even more complex pattern to follow the landform of the site. Three courtyards had different elevations and formed a pattern of terraces of courtyards.

Many natural shapes and forms were observed in Naxi's vernacular buildings. For example, there was a very popular element installed beneath the apex (Figure 18). It was called Xuanyu (literally means hanging fish). Its shape mimicked the "natural shape and form" of fish. This element had two functions: to protect the ridge board as a cover from being damaged by rainwater, and to represent water with its shape of fish. The buildings were built with timber and the most common hazard was fire, so an element in the shape of fish that represented

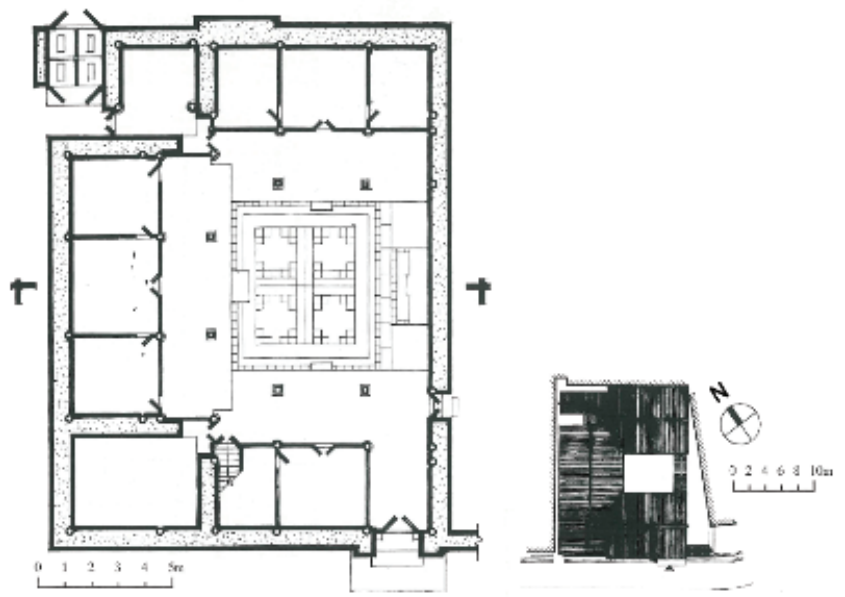

Figure 15. Floor plan of ground level of Case A (left); site plan of Case A. The Lis House, 41, Xinghuo Lane, Qiyi Street built in 1938 (right) (source: Zhu, 2020; personal communication, 18 January)

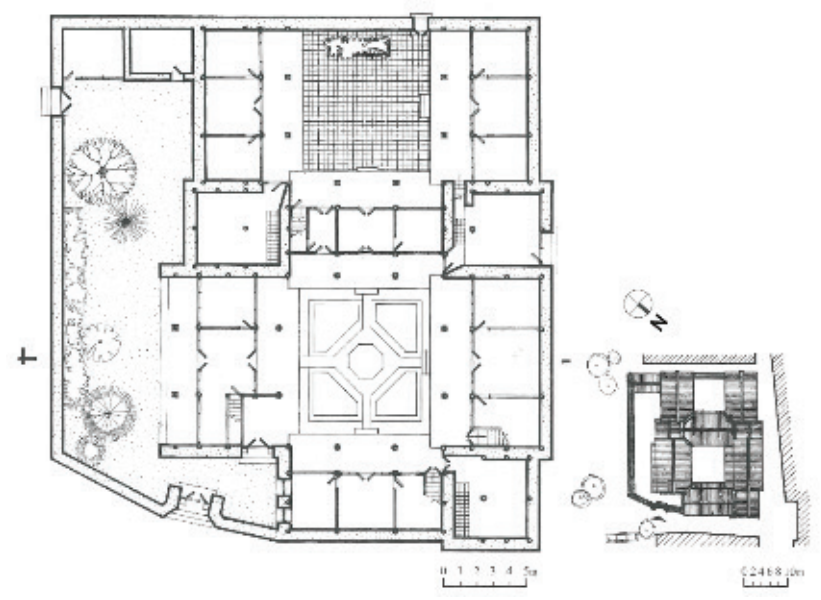

Figure 16. Floor plan of ground level of Case B (left); site plan of Case B. The Zhaos House, 489, Renmin Street built circa 1920 (right) (source: Zhu, 2020; personal communication, 18 January) 
water was seen as an auspicious symbol. Sculptures that mimic the form of animals were found on the ridge (Jiang, 1997a; Yang \& Zhu, 2009).

In the region of the Naxi, it was popular to place a wamao (tile cat) in the middle of the ridge (Figure 19). The tile cat was made of clay, the same material as the tiles. They were made with a big mouth open. According to local people, the tile cat was usually installed to face outside to symbolically absorb wealth and fortune through its big mouth for the family.

There were a large number of engraved patterns that clearly portrayed flora and fauna (Figure 20). They were mainly applied to lattice doors and windows. They also appeared at the end of beams, chapiters and around the gates. Other than carves, openworks, engraves and sculptures, there were paintings and writings along beams. The majority of these paintings and poem writings had a theme of landscape, flora and fauna.

All these details were not only related to "natural shapes and forms", but also had "natural analogues" connotation, including the elements in the shape of hanging fish covering the end of the ridge, tile cat sculptured on ridge and the patterns and paintings that depicted the landscape, flora and fauna. Beyond "connections with nature through the visual system", they were also associated with psychological aspects of prospect, refuge and mystery. Other researchers analysed their cultural significance in enhancing the people and place relationship from different aspects (Jiang, 1997a, 1997b; Yang \& Zhu, 2009).

\subsection{Material}

The Naxi's vernacular buildings were mainly built with local natural materials such as timber, rocks and rammed earth. For recently built buildings and buildings of wealthy people, bricks were used instead of rammed earth. Timber was the commonly used material for constructing the structural framework among different settlements of the Naxi. It was observed that in the comparatively richer areas, such as the Dayan town, which is a popular tourist destination, bricks were mainly used to build walls.

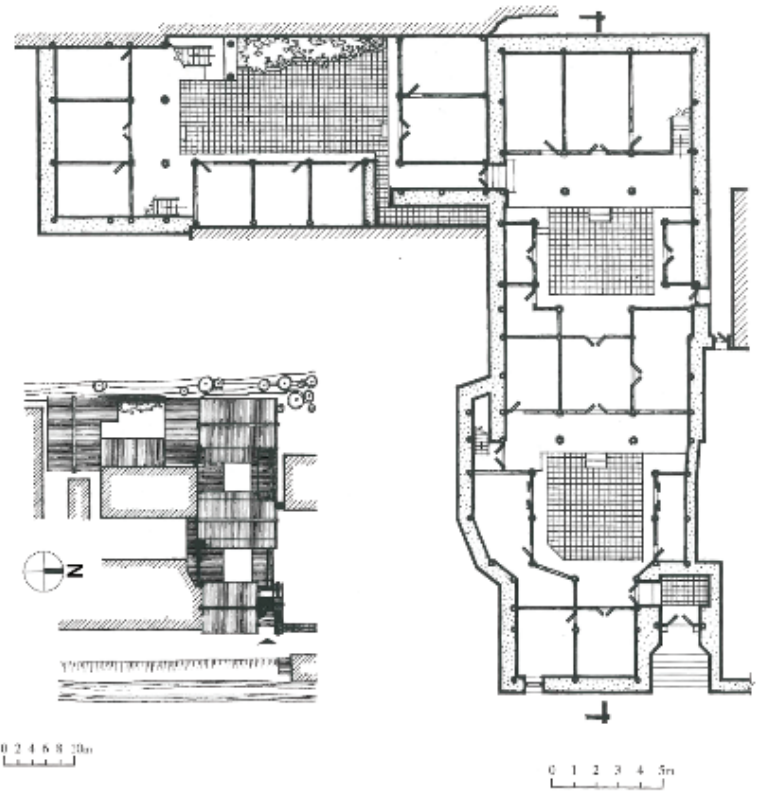

Figure 17. Floor plan of ground level of Case C (left); site plan of Case C. The Hes, 87, Xinhua street built circa 1900 (right) (source: Zhu, 2020; personal communication, 18 January)
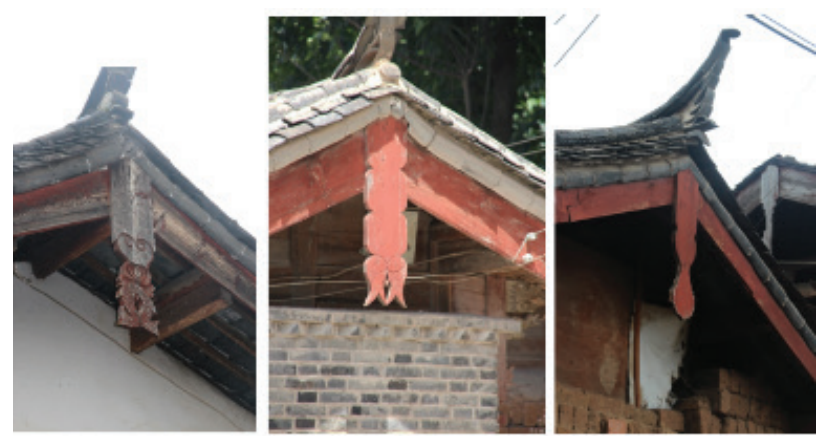

Figure 18. The board mimicking fish hung beneath the apex (photos by the first author)
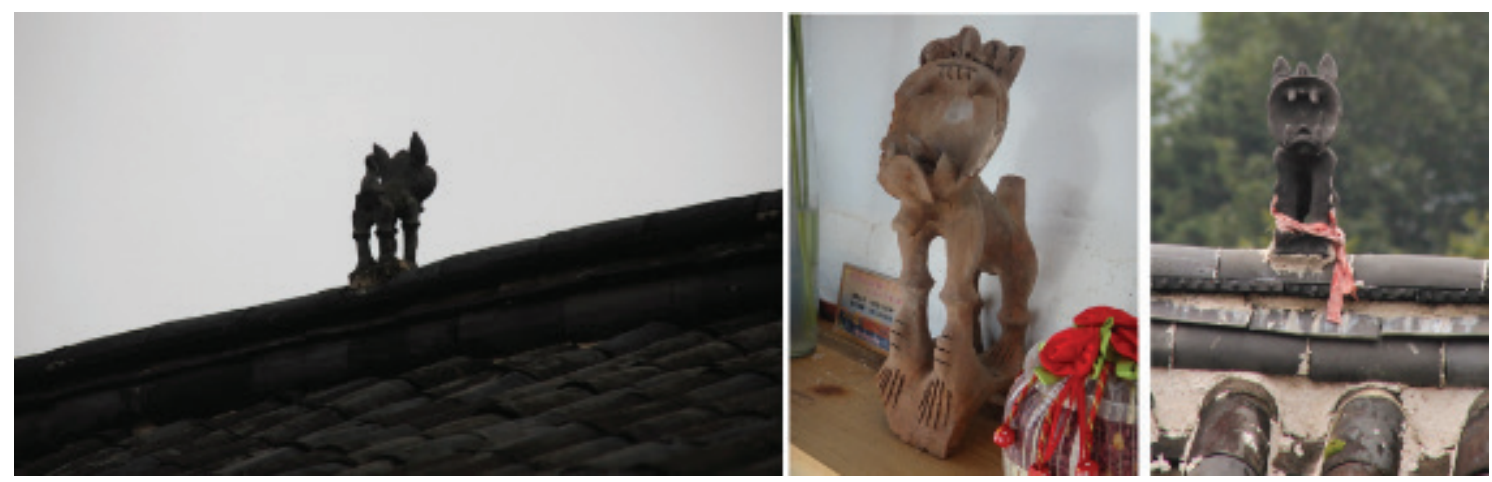

Figure 19. Tile cats (photos by the first author) 

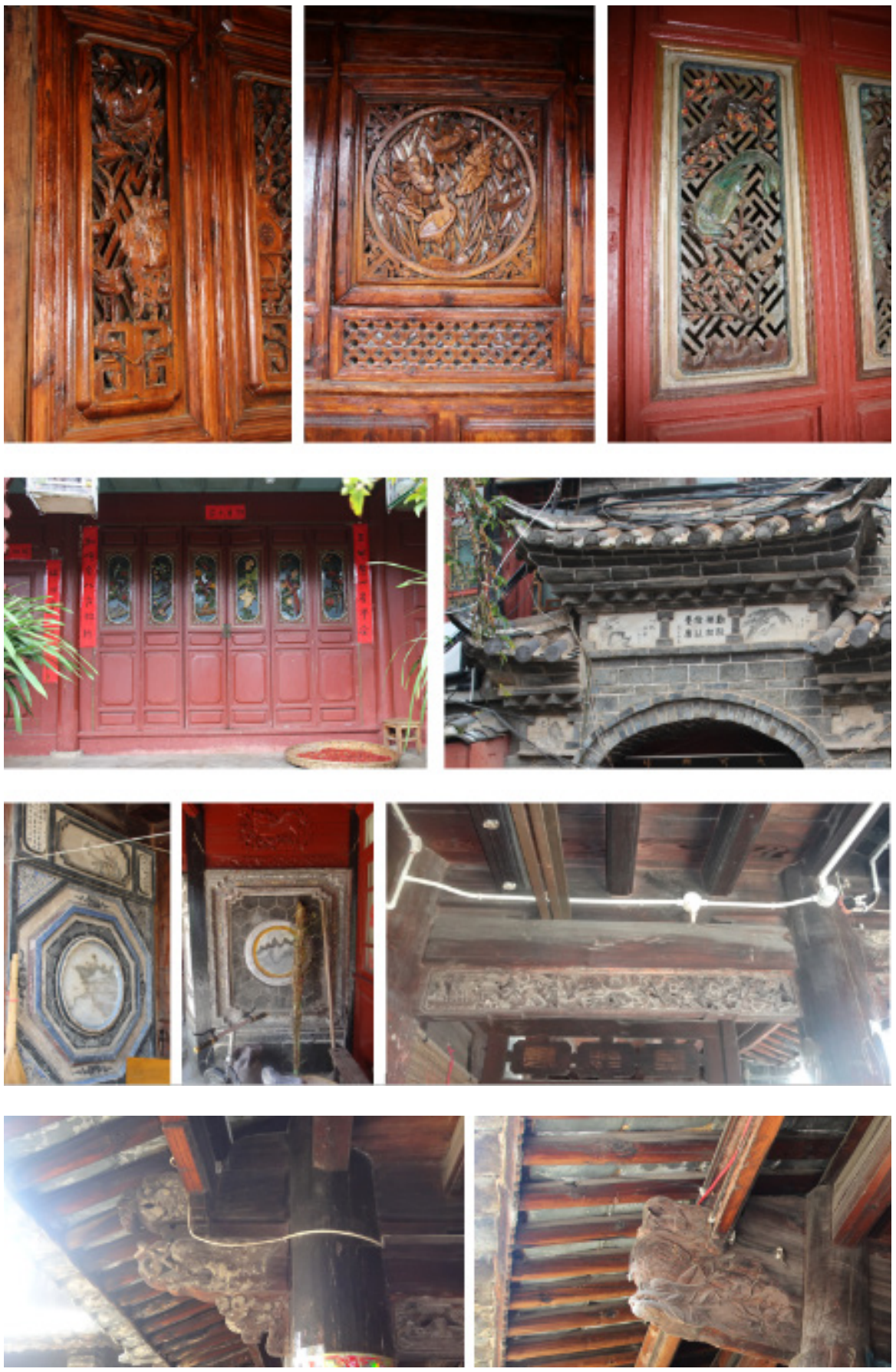

Figure 20. Engraved patterns, paintings, inlaid marbles with a theme of landscape or flora and fauna (photos by the first author)

The façades of buildings that faced the streets were mainly built with timber (Figure 21). For the other three sides of a building, the elevation consisted of three types of different materials from the bottom to the top (Figure 22). Rocks and stones were used for the dado part. The middle part which occupied the largest proportion of the wall was built with bricks. The top part was built with timber, including the gable and part of the enclosure above the windowsills of the upper floor of the building. In less wealthy villages, the middle part was mainly built with rammed earth or adobes (Figure 23). According to the local prac- tice, this choice of materials was due to the following reasons. The more solid materials for the lower part was good to strengthen the walls and improve stability. Home-made bacon and grain were usually stored on the upper floor. The timber-built upper part with certain fenestration was good for ventilation so that it was helpful to keep storage dry and good for preservation. In the northern part of the Naxi's region, which is closer to Yulong Snow Mountain, walls of buildings were all built with stones (Figure 24). Stone buildings enable passive solar direct gain with high thermal mass. This part of the region is cooler and has 


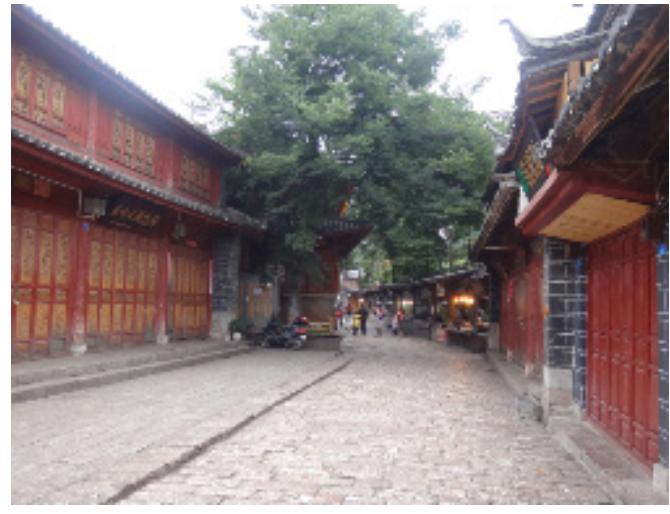

Figure 21. Buildings with the facade constructed with timber (photo by the first author)

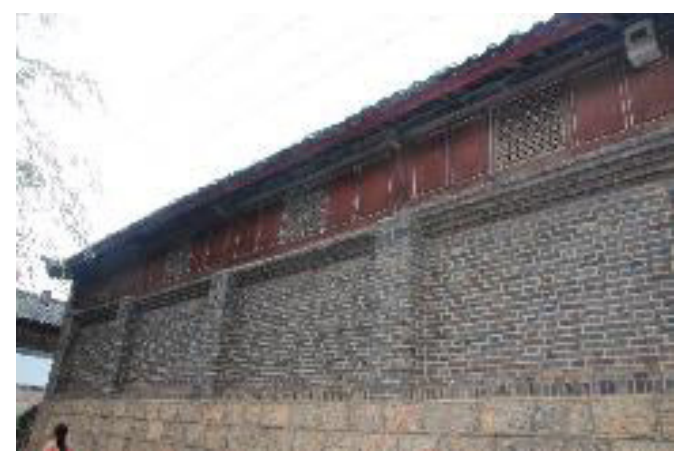

Figure 22. Walls constructed with three types of materials (photo by the first author)

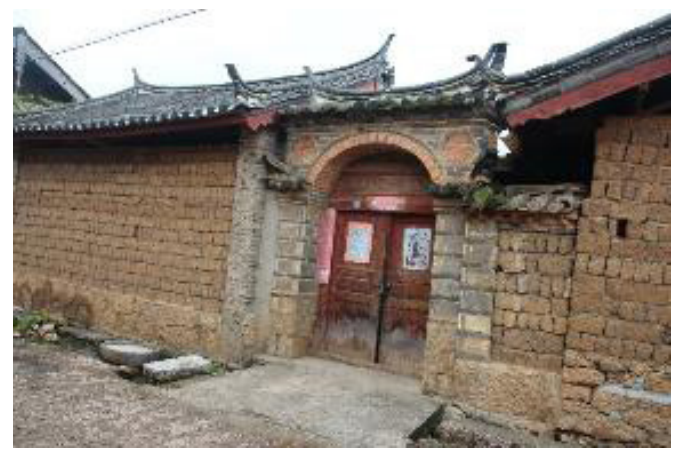

Figure 23. Buildings mainly constructed with adobe in a village of the Naxi (photo by the first author) abundant resources of quarries. Comparing to walls built with bricks or adobes, the much thicker and heavier rock walls with a higher thermal mass are better for thermal performance.

Natural materials were particularly emphasised in the element of environmental features of Kellert's model of biophilic design. Also, in the 14 patterns of biophilic design, the use of natural materials is not only a feature of natural analogues. Also, the natural materials' contribution to tactile sensation is highlighted.

\section{Discussion}

A three-pillar matrix (Figure 2) has been developed and used in this study for observing and analysing the biophilic features in the vernacular architecture and settlements of the Naxi. The proposed three pillars, namely nature, place, and people, allow one to add or remove features according to the specific situation on a case by case basis. For example, in this study of the Naxi's vernacular built environment, region and settlements, grid, streets and circulation, site and building, landscape and materials are highlighted for the biophilic design features (summarised in Table 1), yet this does not mean the biophilic characters of the Naxi's built environment were only limited to these domains. Future studies may expand or deepen this list of criteria. For other cases, the salient domains may vary, such as the vernacular architecture by another ethnic minority group, the Dai, who live in the southeast of the Naxi. The Dai's built form of a building was a "natural analogues" of mimicking a bird. The mimicking is not limited to architectural form but is also expressed in language. The local dialect for calling a building was the same as the calling of a sacred bird. Thus, different from the Naxi's case, the "natural analogue" of the building form is a key feature in the case of the Dai. As another example, for Australian aboriginal people, the location of settlements and huts may be a more important biophilic connection between people and nature.

Some features of vernacular architecture and settlements may have established long-term tradition and belief among the local community, but on face value, this information may appear less scientifically explainable. The
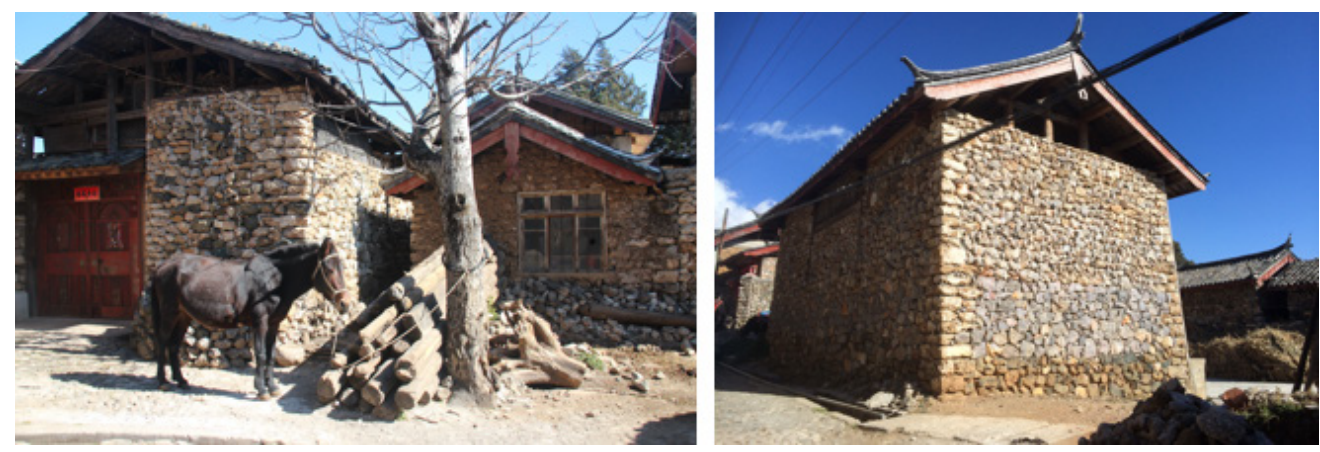

Figure 24. Buildings mainly constructed with stones in a village of the Naxi (photos by the first author) 


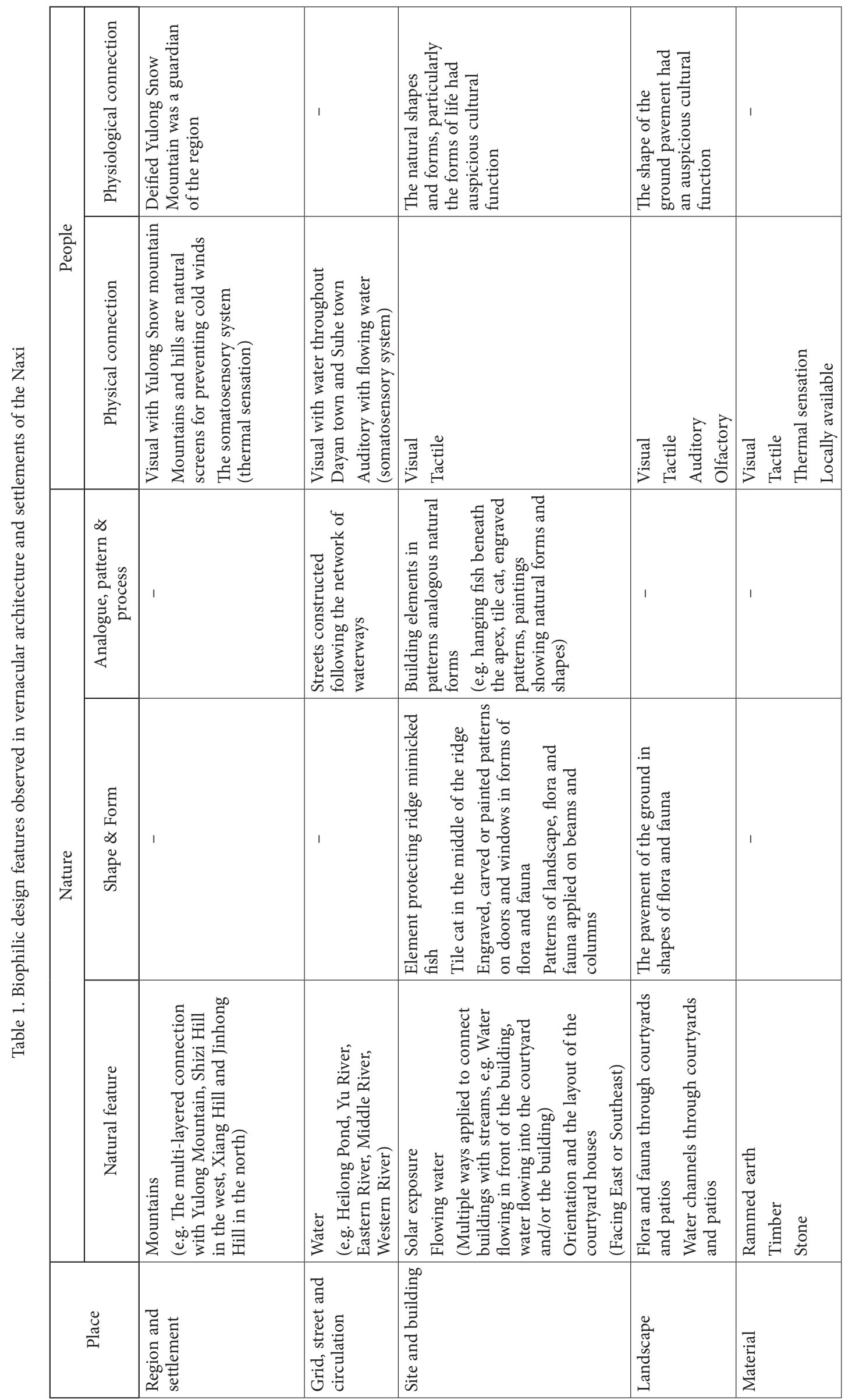


concept of biophilic design provides a bridge between humanist culture and science as well as a multisensory response between physical and psychological domains. For example, the Naxi people live in the region with a high altitude and at the foot of a snow mountain, several features observed in their settlements and buildings seem to have more pragmatic values in a tropical region, including introducing flowing water around buildings, inserting courtyards and patios with a large amount of vegetation, and using permeable pavement for ground cover. However, a need for biophilic connection provides a calibre to the answer. The Naxi had a strong animism culture. Maintaining a connection with nature can be more important than thermal comfort in some scenarios.

For another example, the orthogonal grids of streets are convenient for transportation and more buildable for blocks and buildings along the streets. Here, the biophilic connection with water as well as the practical arrangement with utility offers an explanation for the Naxi's practice of building streets, buildings and amenities following the network of waterways.

In the vision of biophilic design, there can be different emphases between the people and nature depending on the culture. For example, the Naxi's preferred distance from the water is very different from people in other regions of the world, similar to the recognised appropriate distance/connection to flora and fauna and the preferred amount of solar exposure. Even within the same ethnic group, the particular response to biophilic design can vary, such as the choice of materials between different areas of the Naxi. Therefore, biophilic design is not only a universal discourse but also a local response.

More attention to exploring biophilic design features may contribute more local response to this discourse. Louis Kahn said "The artist is only a vehicle for already has been. Nothing can really be given a presence unless it already exists potentially" (Cook et al., 1973). Behind the seemingly less sophisticated face value, the biophilic attributes of vernacular architecture light up potentials for the exploration of biophilic design.

\section{Conclusions}

A focus on the biophilic attributes of vernacular architecture would effectively bridge the domains of "vernacular architecture" and "biophilic design" so that they could benefit each other. A three-pillar matrix for biophilic design: nature, place and people, was developed to observe biophilic design features in vernacular architecture and settlements. We focused on the importance of locality, local people and local community. The matrix developed was applied to observe vernacular architecture settlements of the Naxi.

This article found that the biophilic attributes in vernacular buildings of the Naxi are combinations of interrelated factors such as climate, topography, culture, belief system, convention and arts. Without taking these inter- related factors into consideration, many features can easily be overlooked or cannot be well appreciated. As Timothy Beatley highlighted at the end of his seminal book, public involvement is critical for biophilic design (Beatley, 2017). Rather than being translated through multiple professional stakeholders in architecture and construction, the biophilic features in vernacular architecture provide a valuable resource to understand local communities' response to biophilia. As Bernard Rudofsky described, vernacular architecture as "the architecture without architects" reflects direct and more instinct interactions among the human, built environment and natural environment ( $\mathrm{Ru}-$ dofsky, 1964). For future studies may focus on the clarification of the strengths of each discipline and identification of opportunities for further promoting this observation through multidisciplinary collaboration.

Biophilic design principles provide an accomplished guide to recognise an important aspect of taking people, built environment and natural environment all together into consideration. The proposed three-pillar matrix for observing biophilic design features highlights the importance of the three cornerstones: nature, place and people. Through this observation, it is also recognised that a specific response to a particular biophilic design feature is closely tied with a certain place and certain local community. A future direction can be developed from a more place-based and local community-focused perspective for exploring biophilic features.

\section{Acknowledgements}

This article is based on a study that drew on the support from many colleagues. Inspiring discussions with Xing Ruan, Harry Margalit and Scott Hawken as well as their encouragement were crucial in laying the foundations for this study. Insightful comments and local knowledge from Zhu Liangwen, Wang Dong and Jiang Gaochen and other scholars were also acknowledged. The study was discussed with Tom Clark, Jing Xie and colleagues attending the 2020 UNNC Symposium. Finally, the authors would like to express their thanks to Professor Almantas Liudas Samalavičius, the Editor-in-Chief; anonymous reviewers for their constructive comments; Dovile Vaitkevičienè, and Louis Thevenin for editorial help.

\section{Funding}

This research received no external funding.

\section{Author contributions}

ML: Methodology, Formal analysis, Investigation, Data Curation, Writing - original draft, Writing - review \& editing, Visualisation.

HC: Writing - review \& editing.

LA: Conceptualisation, Validation, Resources, Writing review \& editing, Supervision, Project administration. 


\section{Disclosure statement}

The authors declare that they have no known competing financial interests or personal relationships that could have appeared to influence the work reported in this article.

\section{References}

Alvarsson, J., Wiens, S., \& Nilsson, M. (2010). Stress recovery during exposure to nature sound and environmental noise. International Journal of Environmental Research and Public Health, 7(3), 1036-1046. https://doi.org/10.3390/ijerph7031036

American Society of Heating, Refrigeration, and Air Conditioning Engineers. (2004). Thermal environmental conditions for human occupancy (Standard No. 55-2004). ASHRAE, Atlanta, USA.

Beatley, T. (2017). Handbook of Biophilic city planning \& design. Island Press. https://doi.org/10.5822/978-1-61091-621-9

Browning, W., \& Ryan, C. (2020). Nature inside: a biophilic design guide. Riba Publications. https://doi.org/10.4324/9781003033011

Browning, W., Ryan, C., \& Clancy, J. (2014). 14 patterns of biophilic design: improving health \& well-being in the built environment. Terrapin Bright Green.

Carsten, J., \& Hugh-Jones, S. (1995). About the house: LéviStrauss and beyond. Cambridge University Press. https://doi.org/10.1017/CBO9780511607653

Chen, Z. (2008). Ziran, shenxing yu mei: Xiandai yujing zhong de Naxi zu shenmeijingshen yanjiu [Nature, divinity and beauty: A study of Naxi aesthetics in a modern context] [PhD dissertation]. Shanghai Normal University, Humanities and Communication College.

Cook, J. W., Klotz, H., \& Scully, V. (1973). Conversations with architects: Philip Johnson, Kevin Roche, Paul Rudolph, Bertrand Goldberg, Morris Lapidus, Louis Kahn, Charles Moore, Robert Venturi \& Denise Scott Brown. Lund Humphries.

Eckardt, M. H. (1992). Fromm's concept of biophilia. Journal of the American Academy of Psychoanalysis, 20(2), 233-240. https://doi.org/10.1521/jaap.1.1992.20.2.233

EnergyPlus. (2020). Weather data. https://energyplus.net/weather Erich, F. (1964). The heart of man. Harper \& Row.

Fennell, D. A. (2006). Tourism ethics (Vol. 30). Channel View Publications. https://doi.org/10.21832/9781845410360

Frumkin, P. (2001). Beyond toxicity: Human health and the natural environment. American Journal of Preventive Medicine, 20(3), 234-240. https://doi.org/10.1016/S0749-3797(00)00317-2

Hartmann, H. (1959). Psychoanalysis and moral values. International Universities Press.

He, S. (2001). Naxi wenhua shi [The history of the Naxi culture]. Yunnan minzu chubanshe.

He, Z. (Ed.). (2011). Lijiang guchengzhi [Chronicles of Lijiang]. Yunnan renmin chubanshe.

Heerwagen, J. (2006). Investing in people: the social benefits of sustainable design. In Rethinking sustainable construction. Sarasota, FL.

Hui, F., \& Aye, L. (2018). Occupational stress and workplace design. Buildings, 8(10), 133. https://doi.org/10.3390/buildings8100133

Jiang, G. (1997a). Yunnan zhuwu wenhua. Yunnan daxue chubanshe.

Jiang, G. (1997b). Lijiang: Meili de Naxi jiayuan [Lijiang: the beautiful hometown of the Naxi]. Zhongguo jianzhu gongye chubanshe.
Jo, H., Song, C., \& Miyazaki, Y. (2019). Physiological benefits of viewing nature: a systematic review of indoor experiments. International Journal of Environmental Research and Public Health, 16(23), 4739. https://doi.org/10.3390/ijerph16234739

Kaplan, R., \& Kaplan, S. (1989). The experience of nature: A psychological perspective. Cambridge University Press.

Kellert, S. (2005). Building for life: Understanding and designing the human-nature connection. Island Press.

Kellert, S. (2008). Dimensions, elements, and attributes of biophilic design. In Biophilic design: the theory, science, and practice of bringing buildings to life (pp. 3-19). Wiley.

Kellert, S. (2018). Nature by design: The practice of biophilic design. Yale University Press.

Kellert, S., Heerwagen, J., \& Mador, M. (2008). Biophilic design: The theory, science, and practice of bringing buildings to life. Wiley.

Keniger, L. E., Gaston, K. J., Irvine, K. N., \& Fuller, R. A. (2013). What are the benefits of interacting with nature? International Journal of Environmental Research and Public Health, 10(3), 913-935. https://doi.org/10.3390/ijerph10030913

Knapp, R. G. (1992). Chinese landscapes: the village as place. University of Hawaii Press.

Kremer, P., Hasse, A., \& Hasse, D. (2019). The future of urban sustainability: smart, efficient, green or just? Introduction to the Special Issue. Sustainable Cities and Society, 51, 101761. https://doi.org/10.1016/j.scs.2019.101761

Lévi-Strauss, C. (2008). Structural anthropology. Basic Books.

Li, G. (1991). Dongba wenhua yu Naxi zhexue [Dongba culture and the Naxi philosophy]. Yunnan renmin chubanshe.

Li, M. (2020). The evolution of the zhaobi: physical stability and the creation of architectural meaning. The Journal of Architecture, 25(1), 45-64. https://doi.org/10.1080/13602365.2020.1734049

Liggett, R., \& Milne, M. (2020). Climate Consultant 6. http:// www.energy-design-tools.aud.ucla.edu/climate-consultant/ request-climate-consultant.php

Pan, X. (2014). Naxizu xiangtu jianzhu jianzao fanshi yanjiu [Building paradigm of Naxi vernacular architecture]. Tsinghua University Press.

Ramzy, N. S. (2015). Biophilic qualities of historical architecture: In quest of the timeless terminologies of 'life' in architectural expression. Sustainable Cities and Society, 15, 42-56. https://doi.org/10.1016/j.scs.2014.11.006

Rapoport, A. (1969). House form and culture. Prentice-hall of India Private Ltd.

Ruan, X. (2006). Allegorical architecture: living myth and architectonics in Southern China. University of Hawaii Press. https://doi.org/10.1515/9780824861384

Rudofsky, B. (1964). Architecture without architects: a short introduction to non-pedigreed architecture. University of New Mexico Press.

Ryan, C. O., Browning, W. D., Clancy, J. O., Andrews, S. L., \& Kallianpurkar, N. B. (2014). Biophilic design patterns: emerging nature-based parameters for health and well-being in the built environment. ArchNet-IJAR: International Journal of Architectural Research, 8(2), 62-76.

Söderlund, J. (2019). The emergence of biophilic design. Springer. https://doi.org/10.1007/978-3-030-29813-5

Su, X., \& Teo, P. (2009). The politics of heritage tourism in China: A view from Lijiang. Routledge. https://doi.org/10.4324/9780203873687

United Nations Educational, Scientific and Cultural Organization. (2020). China: Properties inscribed on the World Heritage List (55). http://whc.unesco.org/en/statesparties/CN/ 
Wang, D. (2013). Zuqun, shequn yu xiangcun juluo yingzao: Yi Yunnan shaoshuminzu cunluo weili [Lineage, clan and the formation of rural settlements: In the case of the rural settlements of ethnic minority groups in Yunnan]. Zhongguo jiancai gongye chubanshe.

Wang, J., \& Wang, T. (2008). Naxi yinxiang [Naxi impressions]. Yunnan jiaoyu chubanshe.

Wang, S. (1957). Nanzhao yeshi [The unofficial history of Nanzhao]. Yunnan renmin chubanshe.

Waterson, R. (2013). The living house: an anthropology of architecture in South-East Asia. Tuttle Publishing.

Wen, R. (2008). Kao gong ji [The records of examination of craftsman]. Shanghai guji chubanshe.

Yang, D., \& Zhu, L. (2009). Yunnan minju [Yunnan Vernacular Architecture]. Zhongguo jiancai gongye chubanshe.

Yang, F. (2009). Lijiang Gucheng de diyushehui ji yongshui minsu [The regional society and customs of Lijiang]. Yunan Daxue Xuebao [Journal of Yunnan University], (3), 5-10.
Yigitcanlar, T., Kamruzzaman, M., Foth, M., Sabatini-Marques, J., da Costa, E., \& Ioppolo, G. (2019). Can cities become smart without being sustainable? A systematic review of the literature. Sustainable Cities and Society, 45, 348-365. https://doi.org/10.1016/j.scs.2018.11.033

Zheng, P., \& Liu, Q. (2006). Ren yu ziran de hejie: cong dongbajing kan xiuqusuai kan Naxi ren de ziranguan [The reconciliation between man and nature: Exploring the Naxi's view of nature via xiuqusuai]. Green China, (18), 38-41.

Zhou, W. (1999). Yunnan lishi wenhua mingcheng [The famous historical and cultural towns of Yunnan]. Yunan meishu chubanshe.

Zhu, L. (2005). Lijiang gucheng yu Naxi zu minju [Lijiang old town and Naxi local-style dwelling houses]. Yunnan keji chubanshe.

Zhu, L. (2011). Chuantong minju jiazhi yu chuancheng [Value and inheritance of traditional houses]. Zhongguo jianzhu gongye chubenshe. 